\title{
Post-endarterectomy headache and the role of the oculosympathetic system
}

\author{
Milena De Marinis, Alvaro Zaccaria, Vittorio Faraglia, Paolo Fiorani, Giulio Maira, \\ Alessandro Agnoli
}

\begin{abstract}
A study was carried out on headache after carotid endarterectomy. A specific type of headache, similar in its characteristics to "cluster headache", occurred on the operative side in $30 \%$ of 54 patients, whereas no such headache occurred after extra-intracranial bypass or peripheral vascular surgery. This postoperative headache was not spontaneously reported by $56 \%$ of patients unless they were specifically asked about it. Pharmacological pupillary testing performed in 37 patients revealed that a decreased oculosympathetic activity (with or without adrenoceptor supersensitivity) was constantly associated with post-endarterectomy headache. Although this same abnormality was also observed in $54 \%$ of the patients without headache, a statistically significant $(p<0.01)$ higher prevalence of decreased oculosympathetic responses was found in the patients with headache. The results suggest that damage to the sympathetic plexus due to the surgical procedure is involved in the development of postoperative "cluster-like" headache.
\end{abstract}

Headache frequently occurs in association with different diseases of the internal carotid artery such as thromboembolism, ${ }^{1}$ fibromuscular dysplasia, ${ }^{2}$ carotid dissection, ${ }^{34}$ and endarterectomy. ${ }^{5-7}$

Recently the existence of a trigeminovascular system which supplies intracranial and extracranial arteries has been demonstrated. ${ }^{8}$ It has been suggested that the head pain of migraine and other vascular diseases could be transmitted through this sensory pathway. ${ }^{89}$

Headache which occurs in thromboembolism, fibromuscular dysplasia and carotid dissection, however, is frequently associated with abnormality of the oculosympathetic system. $^{10-12}$ An involvement of the sympathetic plexus in the pathogenesis of these headaches has therefore been suggested..$^{12} 13$

As a model for studying the headache associated with internal carotid artery disease, we studied post-endarterectomy headache. We investigated the incidence and characteristics of this headache and performed pharmacological pupillary testing with the purpose of investigating the oculosympathetic system. The occurrence of postoperative headache was also studied in patients who had extraintracranial by-pass for occlusive lesions of arteries in another vascular region.

\section{Materials and methods}

The occurrence of post-endarterectomy headache was studied in 54 consecutive patients in whom carotid endarterectomy was performed over two years at the Department of Vascular Surgery of the University of Rome. These subjects had a mean (SD) age of $55.8(8.3)$ years. There were 40 males and 14 females. All had had neurological deficits, either TIAs (21 patients) or RINDs (33 patients). Arteriograms revealed stenotic lesions involving the internal carotid artery near the bifurcation (26 right, 28 left) side. Patients with bilateral stenotic lesions, with lesions not directly involving the vessel wall (such as "kinking") of the internal carotid artery, and patients with intracranial aneurysms or arteriovenous malformations, were not included in the study. A comparative group of 25 patients who had had extraintracranial by-pass at the Department of Neurosurgery, Catholic University of "Sacro Cuore", Rome, was also retrospectively investigated (by means of a telephone interview and by consulting the medical records) for the occurrence of headache after the operation. Twenty five patients who received an operative procedure for occlusive vascular disease of the lower limbs were similarly studied. Patients and control subjects who had a history of migraine or other chronic cranio-facial pain were not included. Patients who presented with deterioration of neurological functions and/or disturbance of consciousness after the operation were also excluded. Doppler examination was performed on all patients and control subjects before and after the operation.

Endarterectomy subjects were questioned for the occurrence of unpleasant sensations and specific symptoms by means of a daily postoperative interview particularly, pain in the location of the surgical intervention, dizziness, lightheadedness and headache.

The following features of the headache were recorded: 1) time of onset after surgery, 2) duration and frequency of the attacks, 3) characteristics of pain (continuous-pulsating), 4) pain intensity (mild, moderate, severe), 5) localisation (diffuse, frontal, temporo-parietal, retro-peri-ocular, occipital), 6) lateralisation, 7) associated autonomic symptoms (nausea and vomiting), 8) local autonomic symptoms (conjunctival injection, lacrimation, rhinorrhea, stuffiness), 9) pupil alterations (ipsilateral 
Table 1 Characteristics of post-endarterectomy headache in 16 patients

\begin{tabular}{|c|c|}
\hline Onset after the operation & Mean $=49.5$ hours $($ from 12 to 120$)$ \\
\hline Duration of the attacks & 2-3 hours (from 5 minutes to 6 hours) \\
\hline Frequency of the attacks & 1-2 a day, almost every day \\
\hline Prodromata & None \\
\hline Type of pain & $\begin{array}{ll}\text { Continuous-pulsating } & 9 \\
\text { Pulsating } & 7\end{array}$ \\
\hline Intensity of pain & $\begin{array}{ll}\text { Slight } & 4 \\
\text { Moderate } & 5 \\
\text { Severe } & 7\end{array}$ \\
\hline Localisation & $\begin{array}{ll}\text { Retro-peri-ocular and temporo-parietal } & 9 \\
\text { Fronto-peri-ocular } & 5 \\
\text { Retro-ocular } & 1 \\
\text { Frontal } & 1\end{array}$ \\
\hline Lateralisation & Side of the operation 16 \\
\hline Associated autonomic symptoms (nausea, vomiting) & None \\
\hline Local autonomic symptoms & Conjunctival injection, lacrimation, rhinorrhea, stuffiness \\
\hline Pupil alterations & Horner's syndrome (side of the operation) 4 \\
\hline Persistence after the operation & $\begin{array}{l}\text { Mean }=15 \cdot 79 \text { (from } 2 \text { to } 25 \text { days) } 14 \\
3-4 \text { months }\end{array}$ \\
\hline
\end{tabular}

miosis or mydriasis) and 10) persistence of the headache after operation (days, months).

According to previous studies on migraine and cluster headaches, ${ }^{14}{ }^{15}$ pupillary testing was performed by instillation of sympathomimetic eye drops. In particular phenylephrine $1 \%$ and $5 \%$ (Isonephrine $10 \%$ Tubi Lux Pharma) was used to assess the adrenoceptor sensitivity ${ }^{14}$ and tyramine (tyramine chloride $2 \%$, containing $0 \cdot 1 \%$ sodium merthiolate) was instilled to assess the pre-synaptic noradrenaline release. ${ }^{15}$ The tests were performed as follows: twenty four hours before the operation phenylephrine $1 \%$ was instilled once into both eyes, followed two hours later by phenylephrine $5 \%$. This was repeated 48 hours later. The pupillary responses were evaluated at 15, 30, 60 and 90 minute intervals and expressed as "positive for anisocoria" if a mydriatic or miotic response was noted on the operated side. If an anisocoric response was obtained, a tyramine test was performed 24 hours later. ${ }^{14} 15$

The Chi-squared test was used for statistical analysis.

\section{Results}

Postoperative headache

All 54 patients with carotid endarterectomy spontaneously complained of pain in the location of the surgical intervention, but only eight reported postoperative headache. Only when specifically asked, did six patients complain of dizziness, nine of lightheadedness, 13 of headache. Altogether postoperative headache occurred in 21 patients $(38 \%)$. In five patients

Table 2 Correlation between pupillary alterations and occurrence of "cluster-like" headache in 37 post-endarterectomy patients

\begin{tabular}{lll}
\hline Pupil alterations & "Cluster-like" & $\begin{array}{l}\text { No } \\
\text { headache }\end{array}$ \\
\hline Decreased oculosympathetic responses & 11 & 14 \\
None & 0 & 12 \\
\hline
\end{tabular}

$\chi^{2}=7.51(\mathrm{p}<0.01)$. the headache was diffuse, continuous and of moderate intensity and was attributed to fever in two subjects and to severe hypertension (up to $200 / 120$ ) in the other three. Sixteen patients $(30 \%)$ developed unilateral headache on the side of the surgical intervention with a pattern of pain which resembled "cluster headache". ${ }^{1617}$ Of these patients, $56 \%$ did not spontaneously report the occurrence of headache unless they were specifically asked about it. There were no relationships between age, sex, type of neurological deficit (TIA or RIND), side of the operation, development of other postoperative unpleasant sensations and occurrence of postoperative headache. The headache characteristics are shown in table 1.

Of the patients who had had extra-intracranial by-pass, no patient had postoperative headache other than that commonly experienced after craniotomy. No subjects with peripheral vascular surgery had postoperative headache except one who complained of a moderate and diffuse headache which was attributed to fever.

In all patients and control subjects Doppler examination showed that the operated arteries were patent.

\section{Ocular tests}

Pupil asymmetries were not present before surgery in the 54 patients. Phenylephrine $1 \%$ did not induce any change in pupil size whereas phenylephrine $5 \%$ and tyramine $2 \%$ induced a symmetric mydriatic response. The pupil response was maximal from 30 to 60 minutes after instillation of the test drug. Fifteen patients did not give their consent for the repetition of the ocular tests after the operation but these patients were similar to those who were retested. In particular, the incidence of postoperative "cluster-like" headache was $33 \%$ in the patients who were not retested and $30 \%$ in those who were retested.

Of the 37 patients available for postoperative testing, $25(67 \%)$ presented with anisocoric responses. Eleven showed a mydriatic response 
to phenylephrine $1 \%$ on the operated side, which was more pronounced after phenylephrine $5 \%$. In these 11 patients a reduced mydriatic response on the operated side (miosis) was observed after tyramine $2 \%$. In the other 14 patients a reduced mydriatic response was noticed on the operated side after phenylephrine $5 \%$ and tyramine $2 \%$ instillation.

All patients (11) with headache in whom ocular testing was performed had an oculosympathetic abnormality (table 2). In four of these patients an anisocoric mydriasis was present on the side of the headache after phenylephrine $1 \%$ and $5 \%$ instillation. The same subjects had a reduced mydriatic response (miosis) to tyramine $2 \%$. In seven patients, including four subjects with clinical Horner's syndrome, a reduced mydriatic response (miosis) was observed following phenylephrine $5 \%$ and tyramine $2 \%$ instillation.

Of the 26 patients without headache, in whom ocular testing was possible, only 14 had an oculosympathetic abnormality (table 2 ). In seven of these an increased mydriatic response after phenylephrine $1 \%$ and $5 \%$ instillation and a reduced mydriatic response after tyramine were found on the operated side. In the other seven patients a reduced mydriatic response was observed on the operated side after phenylephrine $5 \%$ and tyramine $2 \%$ instillation.

When looking for a possible correlation between the occurrence of postoperative "cluster-like" headache and the presence of pupillary alterations, a statistically significant higher incidence of decreased oculosympathetic responses was observed in the patients with headache than in those without headache ( $\mathrm{p}<0.01)$, (table 2).

\section{Discussion}

The occurrence of vascular headache following carotid endarterectomy has previously been described..$^{5-7}$ Some authors ${ }^{5}$ have observed that the prevalence of a "cluster-like" headache ${ }^{1617}$ on the operated side was lower than the one we found, while on the other hand there was a higher prevalence of bilateral non-specific headache. The use of different selection criteria and the identification of postoperative unpleasant sensations, which may lead to a misdiagnosis of non-specific headache, may be responsible for these differences. From our data it also appears that post-endarterectomy headache is not a rare condition, but it may not be recognised unless the patients are specifically asked about it.

Where the pathogenesis of post-endarterectomy headache is concerned, mechanical stretching of the artery and vasodilatation could be responsible for the pain. ${ }^{18}{ }^{19}$ It may be that the headache which develops in diseases of the internal carotid artery such as thromboembolism, fibromuscular dysplasia, carotid dissection and endarterectomy may be transmitted through the trigemino-vascular system. ${ }^{8920-22}$

However, the frequent association of the headache with abnormality of the oculosympathetic system suggests that the sympathetic plexus is involved..$^{10-12}$ In addition, the finding that a unilateral vascular headache with ipsilateral pupillary abnormality and hyperhidrosis may occur after injuries to the neck that involve the carotid artery, seems to support this hypothesis. ${ }^{13}$

Pupillary testing showed a post-endarterectomy decrease of sympathetic activity with or without adrenoceptor supersensitivity. In particular pupillary supersensitivity to phenylephrine observed in some patients indicated sympathetic denervation. This was supported by the responses to tyramine in these same patients which confirmed a pre-synaptic abnormality. In other patients a decrease of sympathetic activity without adrenoceptor supersensitivity was found.

Our data show that a decreased oculosympathetic activity was constantly associated with postoperative "cluster-like" headache.

The pupillary alterations, which were very similar to those noticed in migraine and cluster headache $\mathrm{e}^{14}{ }^{15}$ were also present in some patients without headache. Moreover, postoperative headache did not develop in all patients after endarterectomy. The degree and extension of the surgical lesion may have been responsible for the different autonomic and painful responses. The patients with the greatest degree of surgical damage may develop "cluster-like". headache, while those with lesser damage develop autonomic abnormalities but not headache.

As previously reported, ${ }^{23}$ post-operative headache did not occur in patients with extracranial-intracranial by-pass who had received surgical damage localised to another vascular region. In agreement with the observations of Fay, ${ }^{24}$ the stimulation of the internal carotid artery near the bifurcation, seems to be perceived as an ipsilateral craniofacial pain of "cluster headache type".

The mechanism of post-endarterectomy headache remains uncertain. We believe that mechanisms which involve the sympathetic system provide a more interesting explanation than those which involve the trigemino-vascular system.

1 Fisher CM. Occlusion of the internal carotid artery. Arch Neurol Psychiat 1951;65:346-77.

2 Lederman RJ, Salanga V. Fibromuscular dysplasia of the internal carotid artery-A cause of Raeder's internal carotid artery-A cause of Ra

3 Fisher CM. The headache and pain of spontaneous carotid dissection. Headache 1982;22:60-5.

4 Mokri B, Sundt TM, Houser OW, Piepgras DG. Spontaneous dissection of the cervical internal carotid artery. Ann Neurol 1986;19:126-38.

5 Messert B, Black JA. Cluster headache, hemicrania, and other head pains: morbidity of carotid endarterectomy. Stroke 1978;9:559-62.

6 Leviton A, Caplan L, Salzman E. Severe headache after carotid endarterectomy. Headache 1975;15:207-9.

7 Pearce J. Headache after carotid endarterectomy. BMJ 1976;2:85-6.

8 Norregaard TV, Moskowitz MA. Substance P and sensory innervation of intracranial and extracranial feline cephalic arteries. Brain 1985;108:517-33.

9 Moskowitz MA. The neurobiology of vascular head pain. Ann Neurol 1984;16:157-68. 
10 West TET, Davies RJ, Kelly RE. Horner's syndrome and headache due to carotid disease. BMJ 1976;1:818-20.

11 Mokri B, Sundt TM, Houser OW. Spontaneous internal carotid dissection, hemicrania, and Horner's syndrome. Arch Neurol 1979:36:677-80.

12 Gelmers HJ. The pericarotid syndrome. A combination of hemicrania, Horner's syndrome, and internal carotid artery wall lesion. Acta Neurochirurgica 1981;57:37-42.

13 Vijayan N, Dreyfus PM. Post-traumatic dysautonomic caphalalgia. Clinical observations and treatment. Arch Neurol 1975;32:649-52.

14 Fanciullacci M, Galli P, Pietrini U, Sicuteri F. Adrenergic supersensitivity of the pupil in idiopathic headache. Experientia 1977;33:1082-3.

15 Fanciullacci M, Pietrini U, Gatto G, Boccuni M, Sicuteri F. Latent dysautonomic pupillary lateralization in cluster headache. A pupillometry study. Cephalalgia 1982;2: 135-44.

16 Graham JR. Cluster headache. Headache 1972:11:175-85.

17 Headache Classification Committee of the International Headache Society. Classification and diagnostic criteria for headache disorders, cranial neuralgias and facial pain. Cephalalgia 1989;(Suppl 7)8:35-8.
18 Toole JF, Truscott BL, Anderson WW. Clinical management study group. Medical and surgical management of ment study group. Medical and surgical management of
stroke. Stroke 1973;4:273-320.

19 Wolff HG. Headache and other head pain. 2nd ed. New York, Oxford: University Press, 1963.

20 Liu-Chen L-V, Mayberg MR, Moskowitz MA. Immunohistochemical evidence for a substance $P$ containing trigeminovascular pathway to pial arteries in cats. Brain Res 1983;268:162-6.

21 De Marinis M, Martucci N, Gagliardi FM, Feliciani M Agnoli A. Trigeminal control of cranio-facial vasomoto response: I Histamine test in patients with unilateral gasserian ganglion lesions. Cephalalgia 1984;4:243-51.

22 Agnoli A, De Marinis $M$. Trigeminal control of cranio-facia vasomotor response: its possible role in cluster headache. vasomotor response: its possible role in cluster headache. In. Sicuteri F, Vecchiet $L$, Fanciullacci $M$, eds. Trends in 283-91. headache. Amsterdam: Excerpta Medica 1987:

23.

Myers DE, Boone SC, Gregg JM. Superficial temporal
arterial dilatation without headache in extracranialarterial dilatation without headache in extracranial-
intracranial bypass patients. Headache 1982;22:118-21.

24 Fay T. Atypical facial neuralgia, a syndrome of vascular pain. Ann Otol Rhinol Laryngol 1932;41:1030-62. 